\title{
98. Deutscher Röntgenkongress und 8. Gemeinsamer Kongress der DRG \& ÖRG Leipzig, 24. - 27. Mai 2017
}

\section{Einreichung lhres Abstracts ab sofort möglich!}

Sie haben die Möglichkeit Abstracts für die Präsentation eines Vortrags oder eines Posters vom 05. September bis 02. November 2016 einzureichen. Die Einreichung erfolgt ausschließlich online über www.roentgenkongress.de

Nach einer Bewertung Ihres Abstracts erhalten Sie im Januar 2017 eine Informa- tion, ob Sie mit Ihrem Beitrag auf dem RöKo 2017 präsent sein können.

Nutzen Sie diese Gelegenheit um intensiv am wissenschaftlichen Diskurs teilzuhaben.

\section{Portal zur Hotelbuchung geöffnet!}

Suchen Sie bereits heute das passende Hotel, und buchen Sie jetzt Ihr Zimmer in Leipzig!
Sie haben die Möglichkeit, Ihre Reservierung über das Online-Buchungsportal der Messe Leipzig vorzunehmen.

Den Link hierzu finden Sie unter www.roentgenkongress.de.

Alle hier angebotenen Zimmer werden ohne Aufschläge an Sie weitergereicht.

Sollten Sie Fragen oder besondere Wünsche haben, so nutzen Sie die Möglichkeit, sich per E-Mail oder telefonisch mit dem Hotel-Reservation-Team in Verbindung zu setzen:

Tel. +49341 678-8725

Fax: +49 341 678-8722

hotelreservation-roeko@leipziger-messe.de 